\title{
Age Determination and Seasonal Growth of the Dogwhelk Nucella freycineti (Deshayes)
}

\author{
Kei Kawai \\ Marine Biodiversity Laboratory, Faculty of Fisheries, Hokkaido University, Minato 3-1-1, \\ Hakodate, Hokkaido 041-8611, Japan
}

\begin{abstract}
Growth patterns in the shell and soft parts of the dogwhelk Nucella freycinet $i$ were examined. Growth rings in the shells were investigated by X- ray photography and were shown to form annually. In snails that hatched in summer, the first rings formed in the first winter. The shell growth equation was determined based on the age character, population age structure, seasonal growth rate and size frequency distribution of the population. The maximum shell growth occurred in summer. The life span was estimated to be $>11$ years. Low physiological activity and/or starvation induced by low temperature might be main factor(s) causing the formation of annual rings, although age might also influence ring formation. Total body weight increased in late summer in males and from late summer to winter in females. Gonad weight showed a similar trend in each sex. After the reproductive season, shell growth occurred in summer, and body weight increased from summer to winter. These growth characteristics might promote higher survival and fitness.
\end{abstract}

Key words: annual ring, energy allocation, gender, growth, Nucella

\section{INTRODUCTION}

Growth has received considerable attention in life history studies, and the starting point of any comprehensive analysis of life history is the aging of individuals in a population (e.g. Roff 1992; Stearns 1994). Gastropods and bivalves have been aged using rings on their shell surfaces (e.g. Uno 1962; Williamson \& Kendall 1981; Goshima et al. 1991; Kawai et al. 1993). However, many animals have no such distinct characters. In such cases, the size frequency distribution is commonly divided into each age class using the arithmetic probability method described by Harding (1949) (Goodwin 1978; Gardner \& Thomas 1987; Staikou et al. 1988), but this method is not applicable for animals with long life

Received April 14, 2000: Accepted September 22, 2000

* Corresponding author. Present address: Research Center for the Pacific Islands, Kagoshima University, Kourimoto 1-21-24, Kagoshima 890-8580, Japan. spans (Crisp 1984; Tamai 1988).

Energy allocation between growth and reproduction has also been a central topic in life history studies. Many researchers have studied the relationship among reproduction, shell growth and soft part growth in gastropods (e.g. Webber 1970; Stickle 1973). Differences in reproduction and growth between males and females have also been studied. The synchronized reproductive output periods in males and females in Nucella lapillus (see Feare 1970a) and Thais lamellosa (see Stickle 1973) suggest that in both species, males and females have similar body growth patterns. However, males and females of the dogwhelk $N$. freycineti have completely different reproductive cycles (Kawai \& Nakao 1993). Therefore, males and females may have different growth patterns and allocate energy differently.

The objectives of this research were to find shell characters that can be used for aging $N$. freycineti, to determine its growth equation, to examine the growth patterns of soft parts and shells in males and females, and to discuss different energy allocation patterns 
between males and females, and between shells and soft parts.

\section{MATERIALS AND METHODS}

Sampling was carried out monthly at Usujiri ( $41^{\circ} 57^{\prime} \mathrm{N}$, $140^{\circ} 58^{\prime}$ E), Hokkaido, Japan from September 1987 to September 1991. Details of the study site are given in Kawai \& Nakao (1993). To examine the ring formation, about 30 dogwhelks were randomly collected every month at area A (Fig. 1) during spring tide from August 1987 to September 1988. After each shell length was measured with a caliper, the shell was cut from the second spiral rib in the body whorl vertically against the columella. The inside of the shell, including the apex, was removed with a small grinder. About 390 snails treated in this manner were filed using sand paper, steeped in $0.1 \mathrm{~N}$ Hydrochloric acid for 12 hours, and then photographed using X-ray photography (CMB-2, Softex Inc.). Bands in the photos were identified and the shell diameter of each band was measured.

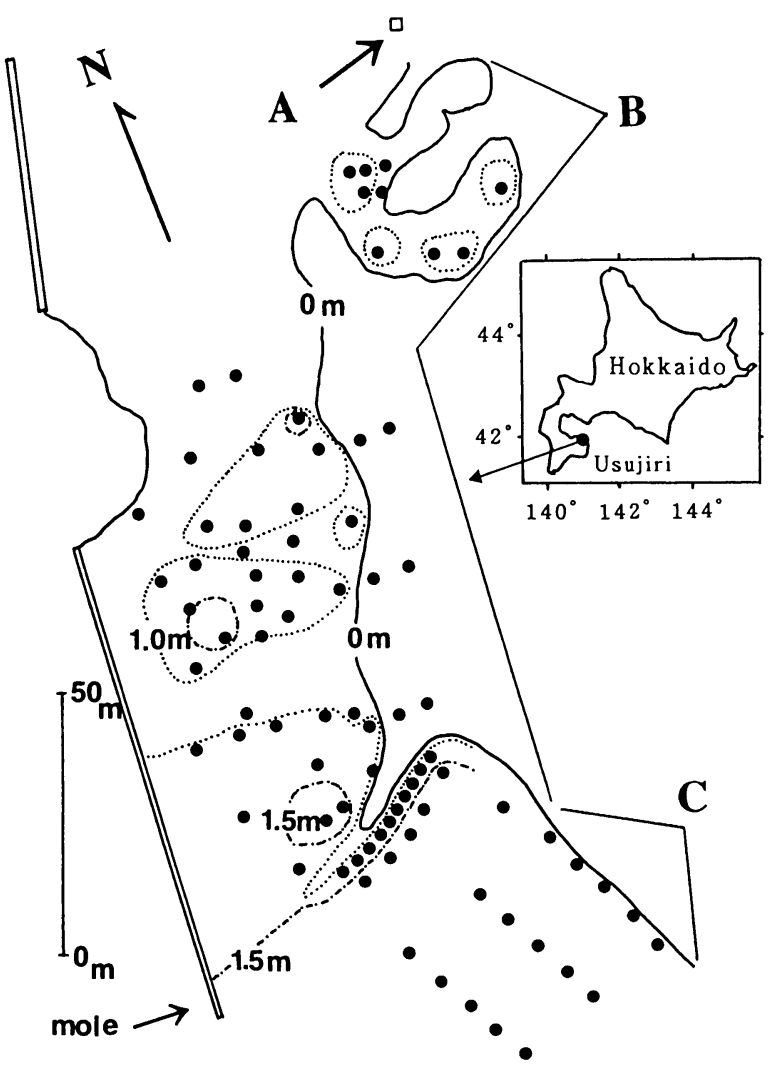

Fig. 1. Map showing the study areas (A, B and C) and approximate height in meter from M.T.L. Black circles show the sampling stations.
To ascertain the reliability of the bands as growth markers, the time and cumulative frequency of their formation were determined by observing the shell edges. To estimate the shell length at the time of band formation, a linear regression equation of shell length against shell diameter was calculated. Since males and females of Neptunea arthritica had different reproductive cycles (Fujinaga 1985) but similar shell growth patterns (Fujinaga 1987), I assumed that the shell growth of Nucella freycineti is also similar between males and females.

To compensate for the problem in the use of the arithmetic probability method for long life-span animals, I divided the monthly size-frequency distributions into each age class based on the age distribution in the field sample determined by ring analysis, and the seasonal growth rate of each age class. The agedistribution study was carried out monthly from December 1987 to December 1988 and from April 1989 to September 1992 at 70 stations (area B) (Fig. 1) using a $1 \times 1 \mathrm{~m}^{2}$ quadrat. Six subtidal stations were observed from December 1987 to December 1988, but eliminated in the latter survey because no dogwhelks were observed at these stations. After measuring their shell lengths in the field, they were returned to their original positions in the field. To determine the age distribution, all dogwhelks at 64 stations were collected in September 1992 and aged by the methods mentioned earlier. To determine the seasonal changes in mean shell length in each age class, samples were collected from 15 stations (area C) (Fig. 1) in June, September, December 1991 and March 1992. Ages in each sample were determined by the method descrived above. The size frequency distributions in area B were divided into each age class using a computer program (Tsutsumi \& Tanaka 1987), based on the population age structure in September 1992 and the seasonal mean shell length of each age class in area C. To construct the growth curve, mean shell lengths at successive growth bands were fitted to the von Bertalanffy equation, which was modified by Moreau (1987) as follows:

$$
\begin{array}{r}
L_{t}=L_{\infty}\left(1-\exp \left(-k\left(t / 12-t_{0}\right)+A \sin \right.\right. \\
\left.\left.\left(2 \pi\left(t / 12-t_{s}\right)\right)\right)\right),
\end{array}
$$

where $L_{t}$ is the shell length (mm) at time $t$ (month), $L_{\infty}$ is the theoretical maximal shell length $(\mathrm{mm}), k$ is a growth constant, $t_{0}$ is the theoretical time (month) when the shell length equals zero, $A$ is $c k / 2 \pi, c$ is a constant of fluctuation in monthly growth, and $t_{s}$ is the time (month) from $t_{0}$ to the beginning of the first fluctuation of shell growth. Parameters of the equation 
were calculated by a computer program using the simplex method (Okumura 1986).

Using the formula describing the relationships among shell length, total soft part dry weight and gonad in each sex (Kawai 1993), and the von Bertalanffy equation determined in this research, monthly dry weights of each part in each age class were calculated. The sizes at maturity of males and females were $15 \mathrm{~mm}$ and $19 \mathrm{~mm}$, respectively (Kawai \& Nakao 1993). For snails smaller than these sizes, the equation for the sex-undetermined class was used.

\section{RESULTS}

Rings as an age character and age determination

Growth rings were clearly observed in the X-ray photos (Fig. 2). White-colored rings were distinguished from black-colored parts. About 5\% of the specimens had formed a new ring by August (Fig. 3). The frequency of dogwhelks with a new ring steeply increased from November, reaching 100\% in February.

The liner regression equation between shell length $(\mathrm{SL})$ and shell diameter (SD) was $\mathrm{SL}=1.48 \mathrm{SD}-0.97$ $\left(r^{2}=0.97, n=50\right)$. The maximum number of rings observed was eleven. The mean $( \pm$ SD) shell lengths for ring $\# 1,2,3,4,5,6,7$ and 8 were $6.01 \pm 2.20,12.05$ $\pm 1.20,16.40 \pm 1.23,19.64 \pm 2.01,23.99 \pm 3.01,25.90$ $\pm 2.20,27.01 \pm 3.05$, and $28.12 \pm 2.10 \mathrm{~mm}$, respectively. The mean shell length of the newly settled dogwhelks in

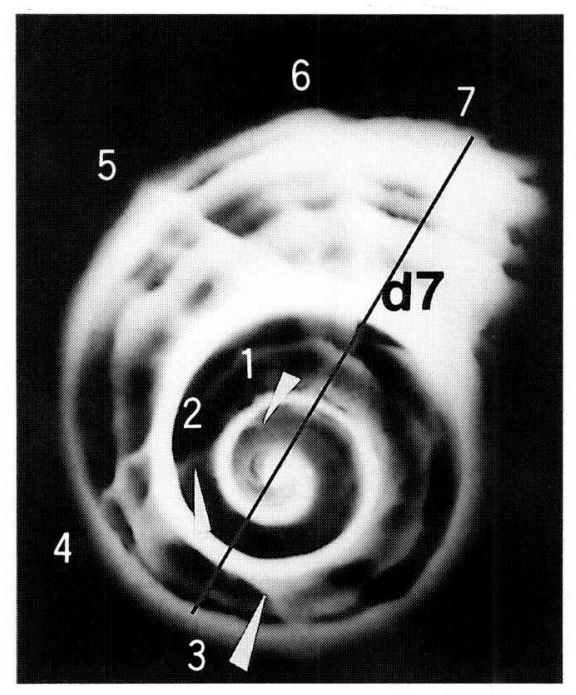

Fig. 2. Growth bands in an adult Nucella freycineti. Numbers show each growth band, and d7 corresponds to the diameter of the 7 th ring formation.

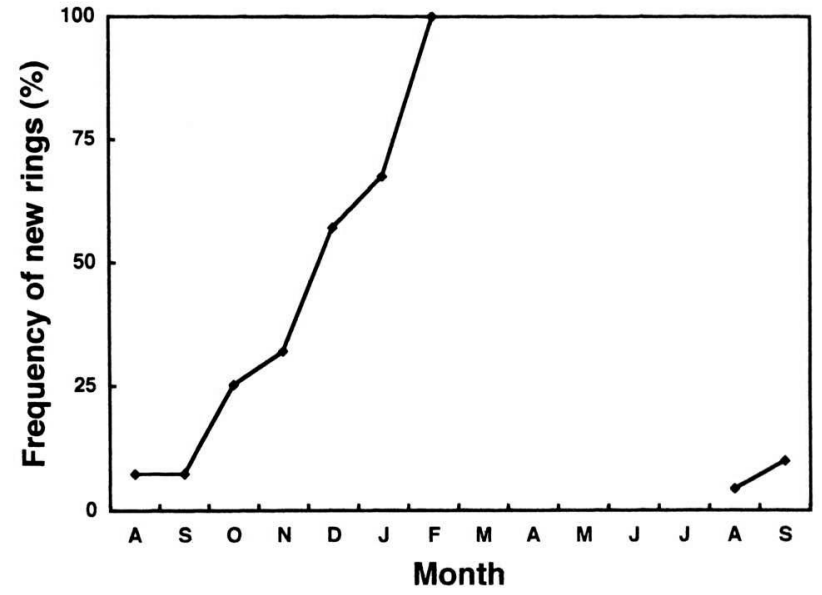

Fig. 3. Diagram showing the proportion (\%) of the animals with a new band at the shell margin from August 1987 to September 1988.
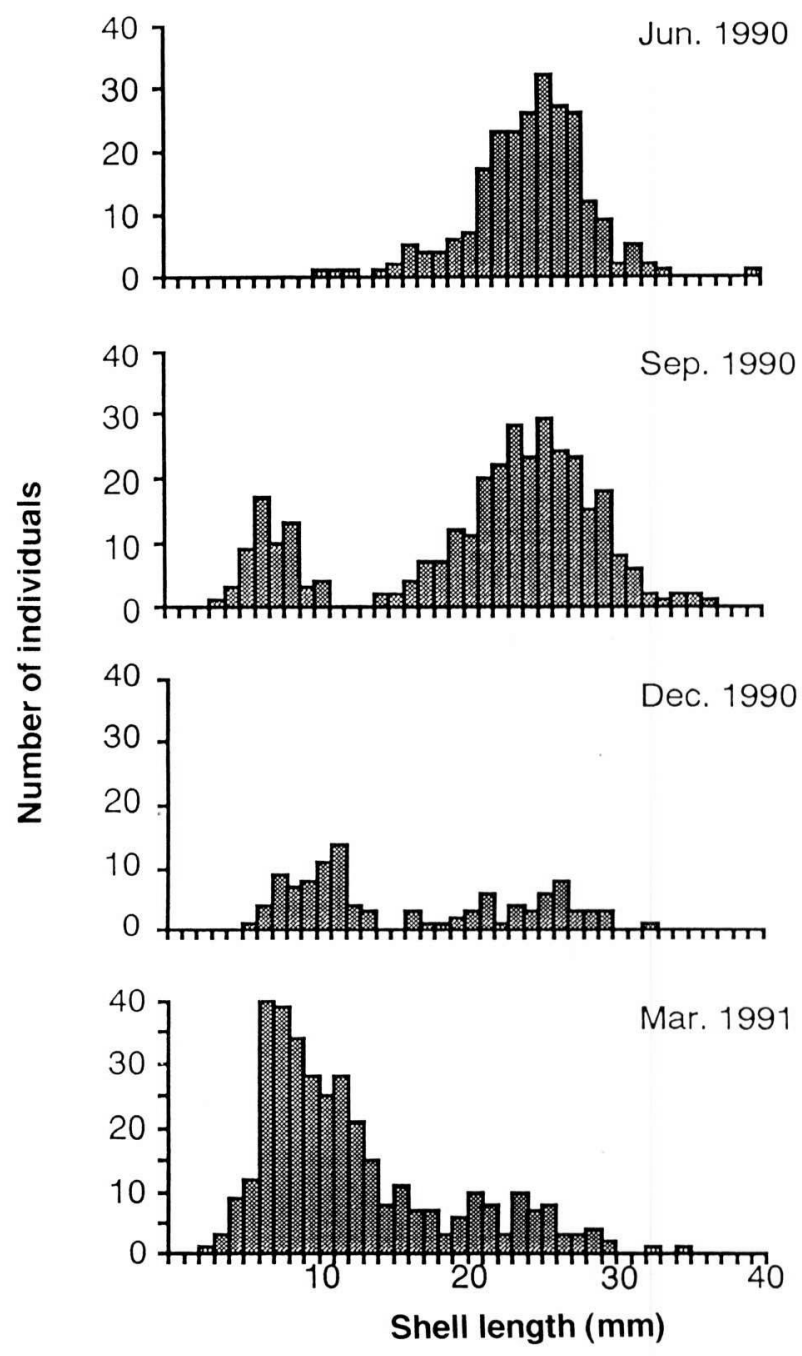

Fig. 4. Size-frequency distribution of shell length at station C from June 1990 to March 1991. 
Table 1. Mean shell length $(\mathrm{mm} \pm \mathrm{SD})$ in each age class from June 1990 to March 1991.

\begin{tabular}{ccccc}
\hline & \multicolumn{4}{c}{ Month } \\
\cline { 2 - 5 } Age & Jun. & Sep. & Dec. & Mar. \\
\hline 1 & & $7.72 \pm 2.54$ & $10.54 \pm 4.14$ \\
2 & $12.75 \pm 2.19$ & 15.02 & $17.91 \pm 0.39$ & $16.67 \pm 1.15$ \\
3 & $18.64 \pm 3.72$ & $19.22 \pm 4.27$ & $19.35 \pm 2.06$ & $21.27 \pm 5.00$ \\
4 & $21.82 \pm 4.69$ & $22.97 \pm 5.25$ & $23.43 \pm 4.64$ & $24.55 \pm 3.35$ \\
5 & $24.46 \pm 3.47$ & $25.13 \pm 6.03$ & $24.58 \pm 3.52$ & $27.58 \pm 8.07$ \\
6 & $26.71 \pm 5.52$ & $28.62 \pm 9.10$ & $27.87 \pm 4.27$ & $27.81 \pm 1.11$ \\
7 & $27.91 \pm 6.54$ & $31.69 \pm 6.95$ & $28.64 \pm 4.87$ & $33.01 \pm 7.05$ \\
8 & $28.70 \pm 2.48$ & 35.61 & & \\
9 & & 37.85 & & \\
\hline
\end{tabular}

February in the field was $5.25 \pm 1.53 \mathrm{~mm}$ and was not significantly different from the mean shell length of ring \#1 ( $U$-test, $P>0.05$ ), suggesting that the first ring recognized in the $\mathrm{X}$-ray photos formed in the first winter for newly hatched snails.

\section{Growth equation}

One main peak was observed in the size-frequency distribution of snails at area C in June 1991, and one more distinct peak appeared in September and December 1991 (Fig. 4). The number of the small-sized snails $(<10$ $\mathrm{mm}$ ) increased in March 1992. Ages of the snails in each month were determined by ring analysis (Table 1). One large and a few small cohorts was observed at area B

Table 2. Monthly mean shell length $(\mathrm{mm})$ and standard deviation in each year class as determined by the growth ring. Samples were taken from 1987 to 1991.

\begin{tabular}{|c|c|c|c|c|c|c|c|c|c|c|c|}
\hline \multirow[b]{2}{*}{ Month } & \multirow[b]{2}{*}{ No. } & \multicolumn{9}{|c|}{ Year Class } & \multirow[b]{2}{*}{1981} \\
\hline & & 1990 & 1989 & 1988 & 1987 & 1986 & 1985 & 1984 & 1983 & 1982 & \\
\hline Dec. 1987 & 1409 & & & & & $11.4 \pm 1.7$ & $16.0 \pm 1.5$ & $19.6 \pm 1.3$ & $22.4 \pm 1.3$ & $25.5 \pm 1.5$ & $29.1 \pm 1.5$ \\
\hline Jan. 1988 & 1449 & & & & & $12.2 \pm 1.6$ & $16.3 \pm 1.6$ & $19.6 \pm 1.4$ & $22.4 \pm 1.3$ & $25.4 \pm 1.4$ & $29.0 \pm 2.0$ \\
\hline Feb. & 1519 & & & & & $12.7 \pm 2.6$ & $18.0 \pm 1.0$ & $21.0 \pm 1.2$ & $24.0 \pm 1.0$ & $26.0 \pm 0.9$ & $29.0 \pm 1.3$ \\
\hline Mar. & 1033 & & & & $6.2 \pm 1.5$ & $11.6 \pm 2.2$ & $16.4 \pm 1.6$ & $20.0 \pm 1.5$ & $23.1 \pm 2.0$ & $26.4 \pm 2.0$ & $31.2 \pm 4.1$ \\
\hline Apr. & 1037 & & & & $7.4 \pm 1.6$ & $12.7 \pm 1.9$ & $17.6 \pm 1.3$ & $21.0 \pm 1.2$ & $24.4 \pm 1.3$ & $27.5 \pm 1.2$ & $30.9 \pm 4.5$ \\
\hline May & 992 & & & & $7.7 \pm 1.7$ & $13.0 \pm 2.4$ & $18.4 \pm 1.6$ & $21.5 \pm 1.5$ & $25.0 \pm 2.0$ & $29.9 \pm 2.5$ & $34.7 \pm 3.2$ \\
\hline Jun. & 1300 & & & & $7.7 \pm 1.7$ & $11.7 \pm 1.7$ & $17.0 \pm 1.7$ & $21.5 \pm 1.1$ & $24.5 \pm 1.1$ & $26.1 \pm 1.8$ & $29.0 \pm 3.0$ \\
\hline Jul. & 1308 & & & & $10.4 \pm 1.5$ & $14.6 \pm 1.6$ & $19.0 \pm 1.3$ & $22.0 \pm 1.0$ & $24.6 \pm 1.7$ & $27.1 \pm 1.6$ & $30.9 \pm 2.0$ \\
\hline Aug. & 1097 & & & & $8.5 \pm 1.7$ & $15.1 \pm 2.4$ & $20.0 \pm 1.7$ & $23.0 \pm 1.3$ & $25.4 \pm 1.5$ & $28.5 \pm 1.6$ & $32.0 \pm 2.3$ \\
\hline Sep. & 1066 & & & & $10.0 \pm 1.8$ & $15.4 \pm 1.1$ & $19.1 \pm 1.1$ & $22.0 \pm 1.2$ & $24.6 \pm 1.2$ & $27.2 \pm 2.1$ & $30.9 \pm 1.7$ \\
\hline Oct. & 1030 & & & & $12.1 \pm 1.2$ & $16.5 \pm 1.5$ & $19.6 \pm 1.3$ & $22.4 \pm 1.4$ & $25.1 \pm 1.4$ & $28.0 \pm 1.8$ & $30.8 \pm 3.1$ \\
\hline Nov. & 812 & & & & $13.0 \pm 3.1$ & $17.2 \pm 2.5$ & $19.8 \pm 1.6$ & $23.2 \pm 1.3$ & $26.0 \pm 1.0$ & $28.0 \pm 1.4$ & $32.0 \pm 1.5$ \\
\hline Dec. & 914 & & & & $12.6 \pm 1.6$ & $17.4 \pm 1.8$ & $21.1 \pm 1.1$ & $24.0 \pm 1.2$ & $27.6 \pm 1.4$ & $32.0 \pm 0.9$ & \\
\hline Apr. 1989 & 457 & & & $5.6 \pm 5.7$ & $12.3 \pm 2.3$ & $17.5 \pm 1.4$ & $21.5 \pm 1.0$ & $24.4 \pm 1.1$ & $27.6 \pm 0.8$ & & \\
\hline Apr. 1990 & 540 & & $8.0 \pm 1.1$ & $13.0 \pm 1.4$ & $17.0 \pm 1.8$ & $21.0 \pm 1.7$ & $25.0 \pm 1.0$ & $27.5 \pm 1.3$ & $32.0 \pm 1.5$ & & \\
\hline May & 606 & & $6.1 \pm 2.0$ & $13.2 \pm 1.4$ & $17.4 \pm 1.5$ & $21.3 \pm 1.8$ & $24.4 \pm 1.3$ & $27.6 \pm 1.3$ & $32.0 \pm 1.8$ & & \\
\hline Jun. & 779 & & $8.0 \pm 1.6$ & $12.9 \pm 2.1$ & $18.6 \pm 1.3$ & $21.6 \pm 1.3$ & $24.4 \pm 1.5$ & $28.0 \pm 2.0$ & $32.4 \pm 2.5$ & & \\
\hline Jul. & 612 & & $8.0 \pm 0.9$ & $12.0 \pm 1.0$ & $19.0 \pm 1.6$ & $22.0 \pm 1.2$ & $24.7 \pm 1.4$ & $26.9 \pm 1.8$ & $29.8 \pm 2.2$ & & \\
\hline Aug. & 470 & & $12.0 \pm 1.1$ & $15.0 \pm 3.1$ & $19.0 \pm 1.2$ & $22.0 \pm 1.4$ & $25.4 \pm 1.9$ & $29.0 \pm 1.5$ & $32.1 \pm 1.9$ & & \\
\hline Sep. & 454 & & $12.0 \pm 1.8$ & $14.0 \pm 0.9$ & $19.5 \pm 2.2$ & $23.0 \pm 1.8$ & $26.0 \pm 1.8$ & $29.1 \pm 1.4$ & $32.1 \pm 1.7$ & & \\
\hline Oct. & 475 & & $9.0 \pm 2.2$ & $14.0 \pm 1.8$ & $19.6 \pm 1.8$ & $23.0 \pm 1.1$ & $26.0 \pm 1.4$ & $29.0 \pm 1.0$ & $32.0 \pm 1.2$ & & \\
\hline Nov. & 468 & & $11.6 \pm 1.5$ & $15.0 \pm 0.7$ & $19.0 \pm 1.3$ & $22.4 \pm 1.4$ & $26.0 \pm 1.7$ & $29.0 \pm 1.4$ & $31.8 \pm 1.8$ & & \\
\hline Dec. & 547 & $5.0 \pm 0.0$ & $12.1 \pm 1.9$ & $16.0 \pm 1.2$ & $19.5 \pm 1.9$ & $22.5 \pm 1.3$ & $25.0 \pm 1.1$ & $28.3 \pm 1.5$ & $33.0 \pm 1.6$ & & \\
\hline Jan. 1991 & 540 & $6.0 \pm 0.0$ & $10.2 \pm 1.3$ & $18.0 \pm 2.0$ & $20.9 \pm 1.4$ & $23.6 \pm 1.0$ & $26.0 \pm 0.7$ & $28.0 \pm 0.6$ & $30.9 \pm 2.0$ & & \\
\hline Feb. & 308 & $6.3 \pm 2.5$ & $12.5 \pm 1.3$ & $16.9 \pm 1.4$ & $21.1 \pm 1.3$ & $24.5 \pm 1.7$ & $25.6 \pm 2.4$ & $30.7 \pm 2.6$ & & & \\
\hline Mar. & 471 & $5.8 \pm 1.3$ & $10.7 \pm 2.4$ & $17.6 \pm 2.5$ & $20.9 \pm 2.1$ & $24.2 \pm 1.5$ & $27.0 \pm 2.1$ & $32.0 \pm 1.9$ & & & \\
\hline Apr. & 561 & $7.0 \pm 0.9$ & $11.8 \pm 0.7$ & $17.5 \pm 2.0$ & $22.0 \pm 1.5$ & $24.7 \pm 0.8$ & $26.9 \pm 1.8$ & $31.1 \pm 2.5$ & & & \\
\hline May & 554 & $8.9 \pm 0.7$ & $13.1 \pm 1.9$ & $17.6 \pm 1.1$ & $20.7 \pm 0.9$ & $23.2 \pm 1.5$ & $26.6 \pm 2.2$ & $30.8 \pm 3.3$ & & & \\
\hline Jun. & 513 & $6.0 \pm 5.4$ & $13.1 \pm 1.2$ & $18.0 \pm 1.8$ & $21.4 \pm 1.3$ & $24.6 \pm 1.1$ & $27.0 \pm 1.8$ & $32.0 \pm 0.9$ & & & \\
\hline Jul. & 549 & $8.0 \pm 2.1$ & $14.1 \pm 1.5$ & $18.7 \pm 1.1$ & $21.5 \pm 1.1$ & $24.5 \pm 1.3$ & $27.0 \pm 2.1$ & $30.4 \pm 4.7$ & & & \\
\hline Sep. & 549 & $7.8 \pm 1.5$ & $15.0 \pm 2.2$ & $19.6 \pm 1.3$ & $22.3 \pm 1.5$ & $24.8 \pm 1.3$ & $26.9 \pm 2.0$ & $30.1 \pm 5.1$ & & & \\
\hline
\end{tabular}



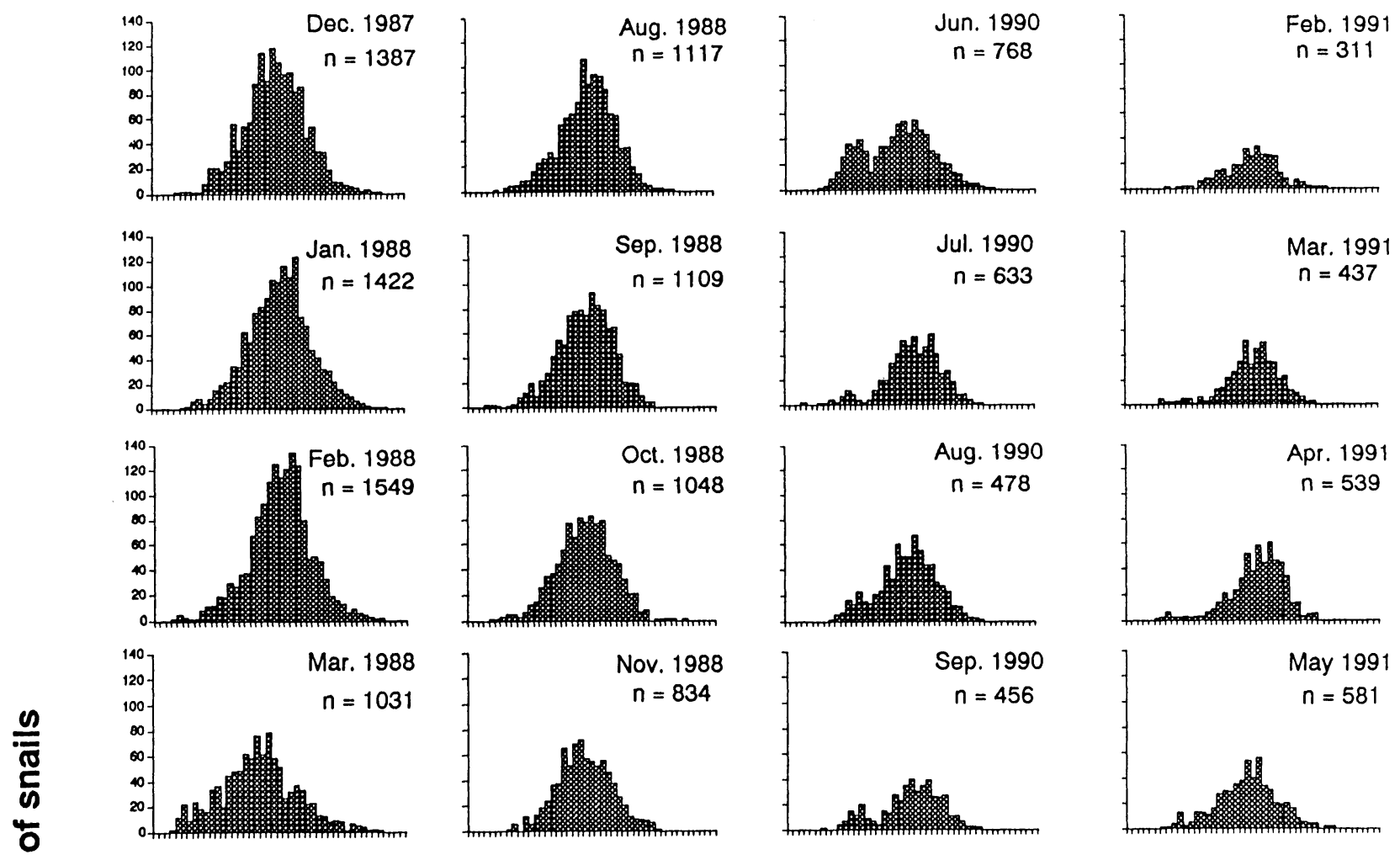

है
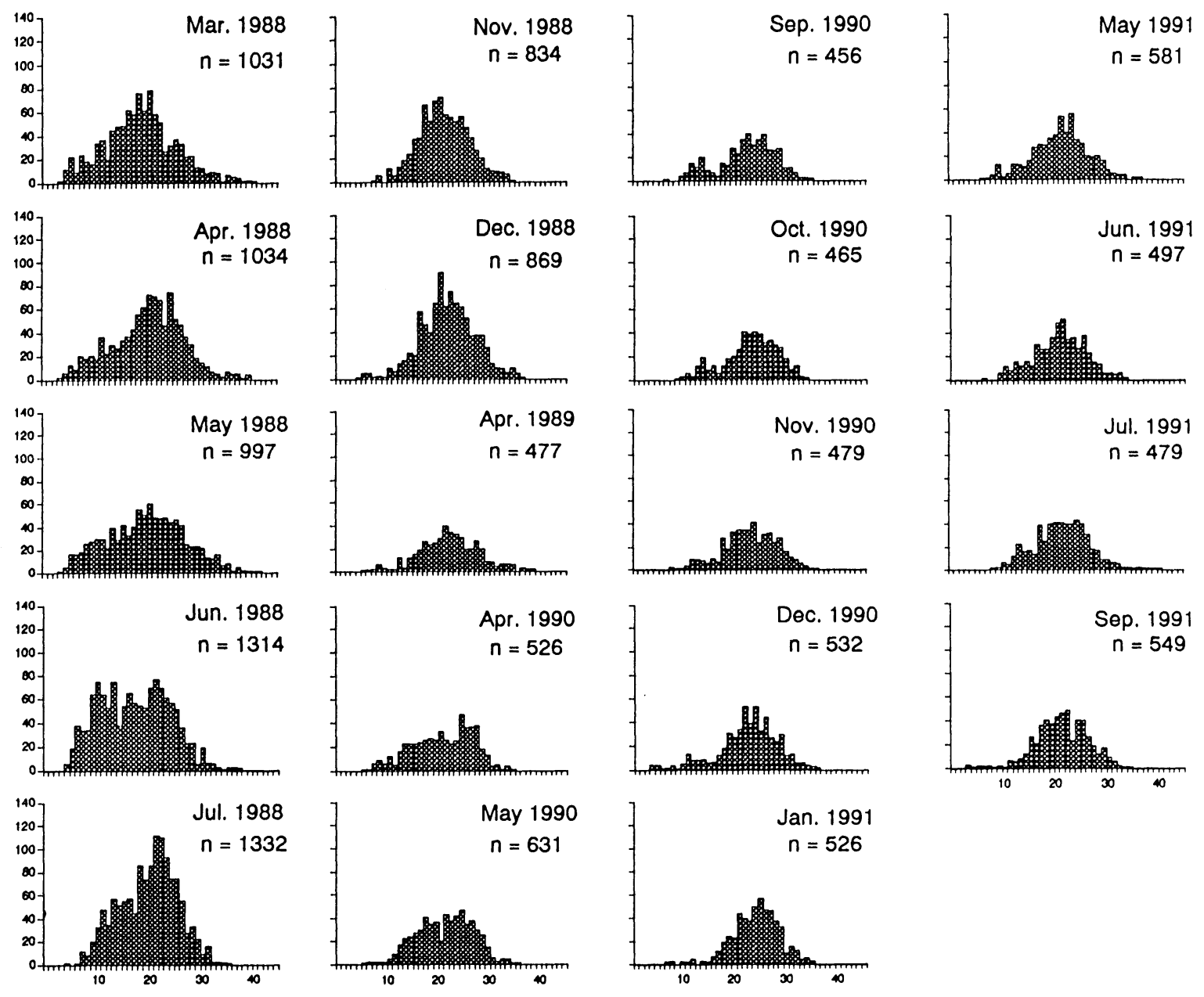

\section{Shell length $(\mathrm{mm})$}

Fig. 5. Size-frequency distribution of shell length at station B from December 1987 to September 1991. 


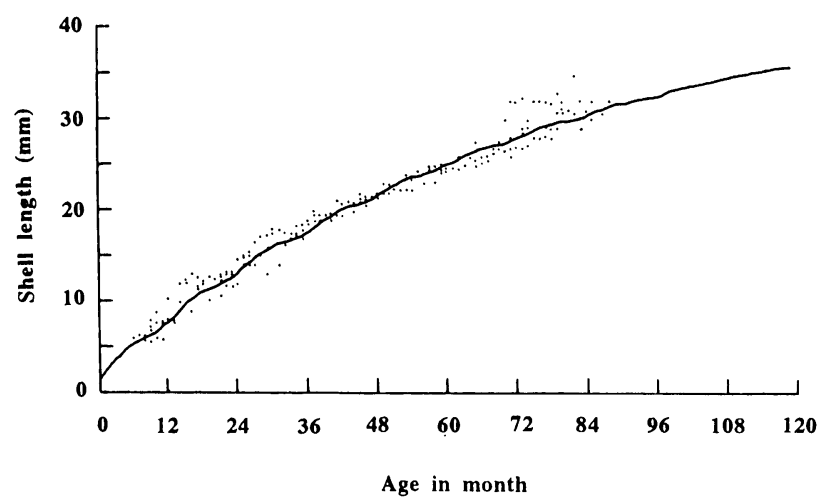

Fig. 6. The growth curve for shell length versus age in months. Dots show monthly mean shell length in each age class.

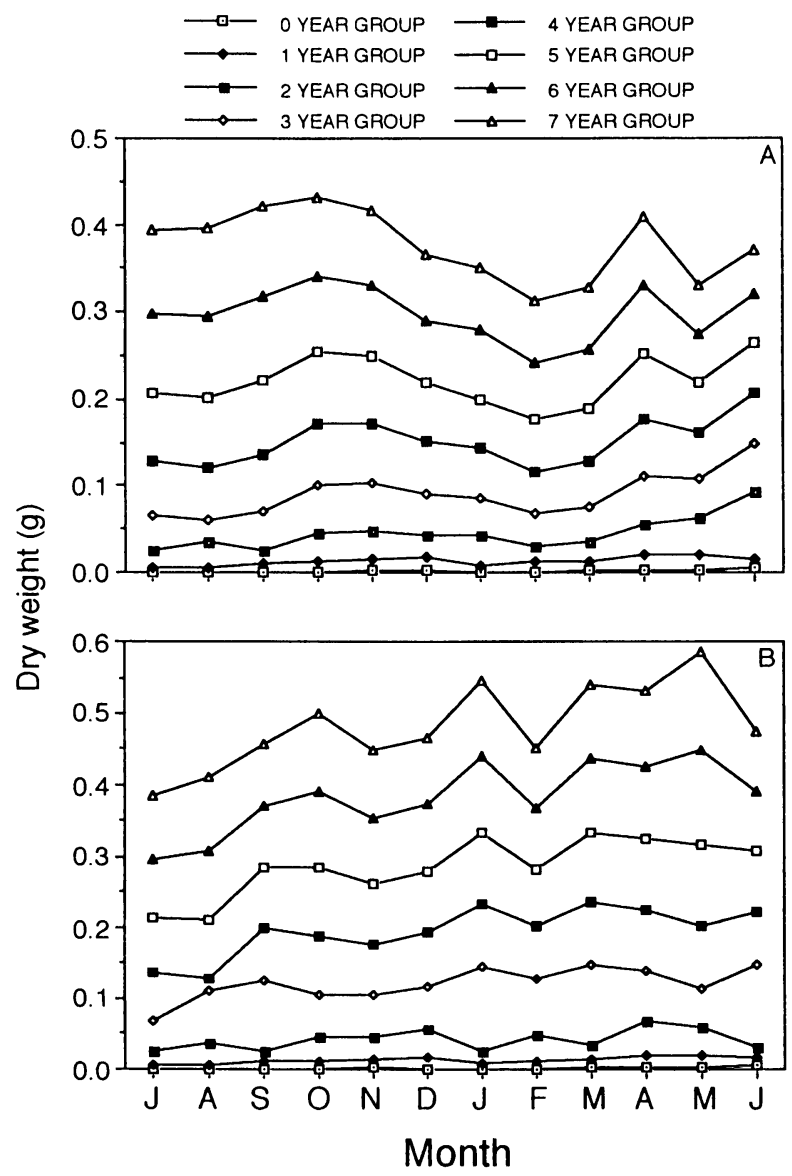

Fig. 7. Growth curve in total body weight (g) for each age group of males (A) and females (B). from December 1987 to September 1991 (Fig. 5). The monthly size-frequency distribution was divided into about 7 age classes (Table 2) based on the age distribution in September 1991 in area B and seasonal growth rate in area $\mathrm{C}$.

On the basis of the mean shell length at each ring, the growth equation was calculated as follows (Fig. 6):

$$
\begin{array}{r}
L_{t}=44.66(1-\exp (-0.16(t / 12+0.27)+ \\
0.01 \sin (2 \pi(t / 12-0.63))))
\end{array}
$$

\section{Growth of soft parts}

Fig. 7 shows the seasonal changes in total body weight in each sex. In males, body weight increased from August, but decreased from October until February in 5- to 7-year-old specimens. Likewise, younger male snails decreased in weight from December to February. On the other hand, the weights of females increased from September to February or April, although there was a fluctuation during this period. The seasonal pattern of testis weights was distinctly different from that of ovary weights (Fig. 8). In males, the highest value was observed in October, but in females the highest value was observed from February to April.

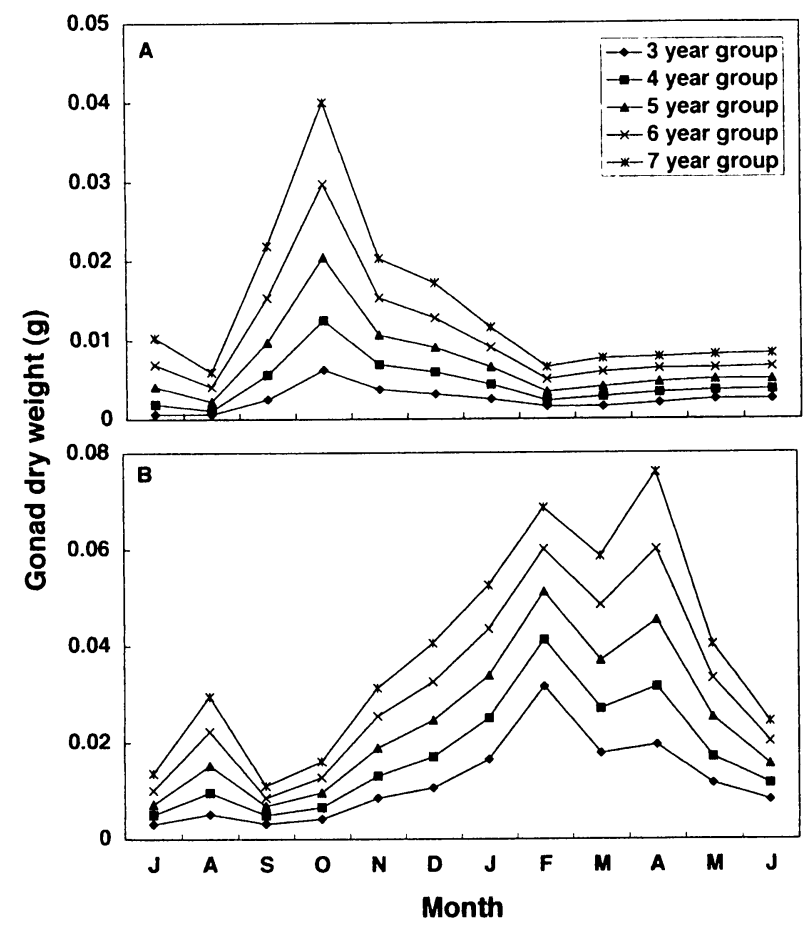

Fig. 8. Growth curve expressed in gonad dry weight (g) for each age group of males (A) and females (B). 


\section{DISCUSSION}

In the present study, rings were observed with X-ray photography and used as growth markers. Generally, such rings are observed on the shell surface in marine gastropods (e.g. Uno 1962; Williamson \& Kendall 1981). However, it is very difficult to observe these rings in $N$. freycineti because the shell surface in this species is complicated. In this case, examination by Xray photograph is a very useful method.

Many biological (predator, availability of prey, reproduction, sex, and age) (Moore 1938; Feare 1970b; Palmer 1983; Chow 1987; Erlandsson \& Johannesson 1994) and physical factors (temperature, microhabitat, and wave action) (Ekaratne \& Crisp 1984; Gosselin \& Bourget 1989; Etter 1994) can influence shell growth in gastropods. The effect of temperature, reproduction and availability of prey can be periodical. Rings in Nucella freycineti formed annually (Fig. 3), and the first rings formed during the first winter in newlyhatched snails. The reproductive periods differ between the sexes (Kawai \& Nakao 1993). The copulating period was from October to April, and females produced egg capsules from April to June. Moreover, the age at first maturation was 2.5 and 3.5 years old in males and females, respectively. The main prey of $N$. freycineti is the mussel Septifer virgatus (see Kawai 1993), and the mussel density remained high throughout the year. This suggests that there was enough prey available through the year at Usujiri. However, the lowest temperature in the research area occurred in February. When temperatures are low, dogwhelks aggregate in crevices, stop feeding and decrease their physiological activity (Kawai 1993; see also Largen 1967; Feare 1971). On the other hand, although all individuals had formed rings by winter, rings formed as early as August in the same specimens (Fig. 3). N. lapillus shells stop growing when they reach the mature size (e.g. Fear 1970b), however shells of $N$. freycinet $i$ continuied to grow slightly after reaching this size (Fig. 6). Because shell growth was highest in summer in this study, shell growth of large adult dogwhelks might occur only in summer and stop in the other seasons. Therefore, ring formation would start after summer in large adults, and the rate of individuals with rings might continuously increase until winter. Accordingly, decreasing temperatures and/or starvation induced by low temperature might be the main factor(s) that cause the annual rings of $N$. freycineti to form. Moreover, size might also influence the time of ring formation.
Different body growth patterns were observed between the sexes (Fig. 7). The cost of reproduction, availability of prey and starvation induced by low temperatures are considered the main factors that affect the seasonality of body weight of Thais (Nucella) lamellosa (see Stickle 1973), and the cost of reproduction (oxygen consumption and decrease of body weight) is very high in both sexes. In a laboratory study, most female Neptunea antiqua died within 3 months after spawning due to exhaustion (Pearce \& Thorson 1967). In the present study, the body weight of Nucella freycineti decreased considerably in the copulating period in males and spawning period in females (Fig. 7). On the other hand, the lowest water temperature was observed in February. Body weight of females slightly dropped in February but soon increased in March. The lowest value in males occurred when water temperatures were low. However, this coincided with the main copulating period (from December to February) (Kawai \& Nakao 1993). As mentioned before, many prey were present in the habitat of the dogwhelks. Therefore, reproduction could be a more influential factor on body growth, although starvation induced by low temperature might also have an effect.

The timing of allocation of food intake and energy storage has been the focus of recent life history studies (Doughty \& Shine 1998). The soft parts (foot and digestive gland) of gastropods function to store energy (Webber 1970; Stickle 1973). N. lapillus does not feed at low temperatures (especially below $5^{\circ} \mathrm{C}$ ) in the laboratory (Largen 1967). Winter water temperature in the present research area was about $2^{\circ} \mathrm{C}$, and feeding in the field is seldom observed in winter (Kawai \& Nakao 1993). Although female body weights were high in winter, shells did not grow in winter (Figs. 3 and 7). This suggests that stored energy was not allocated into shell formation in winter. On the other hand, the maximum shell growth rate was observed in summer (Fig. 6 and Table 1). Feeding activity in the field is very high in summer (Kawai \& Nakao 1993), and body weights in both sexes were relatively light. Therefore, the energy from food intake might be directly allocated into shell growth in summer.

Testes matured rapidly in September (Fig. 8; see also Kawai \& Nakao 1993). Body weights increased from September. Feeding activity of $N$. freycinet $i$ in the field is higher from summer to autumn (Kawai \& Nakao 1993). Both growth patterns of testes and body weight corresponded with feeding activity. Accordingly, the maturation of testes was synchronized with body growth, and energy for both testes and body 
weight was supplied by food intake. On the other hand, ovaries developed in winter. However, body weight of females did not decrease even in winter in spite of their low feeding activity. Energy from food was first stored in the body, and then the ovary eventually developed from the energy stored in the foot or digestive gland.

Both sexes showed different reproductive cycles and body growth patterns (Figs. 7 and 8 ). Males matured before winter, while females matured after winter. The origin of the energy supply for testes and ovaries might be different. Doughty \& Shine (1998) showed that reptile females with large energy stores produce large litters in the following year. Because of low temperatures, dogwhelks can not feed during winter (Kawai \& Nakao 1993). But females need to store much energy for wintering and spawning, because the cost of female reproduction is very high (Stickle 1973) and feeding activity in winter is very low in $N$. freycineti. This suggests that the feeding activity of female dogwhelks before winter strongly influence reproduction in the following spring as well as the survival rate during winter. On the other hand, males started copulation from October. Because dogwhelks aggregate in winter, males can easily find females to copulate. Therefore, the amount of allocation of intake energy into testis will directly influence fitness. Because of this energy allocation, survival rates might decrease in winter, but males can increase their fitness.

Shell growth occurred in summer and body weight increased from summer to winter. Larger shell size helps increase the tolerance against lethal environmental factors (predator, desiccation and wave action, etc.) in many gastropods (Hughes 1986). The mortality of $N$. lapillus decreases with increasing size (Feare 1970b). On the other hand, generally soft part growth and the reproductive output were usually restricted by the volume of the shells, and larger snails have bigger shell volumes. Therefore, the early growth period of shells prior to the growth of soft parts increases the ability to store enough energy during winter and will result in higher reproductive outputs. This means that these growth patterns increase the survival rates and fitness.

Acknowledgments. I am grateful to A. Fuji, S. Nakao and S. Goshima for their advice during the study and to G. Shinohara for his technical support on X-ray photography. I also thank A. Ilano for improving the English text and the members of the Marine Biodiversity Laboratory and Usujiri Marine Station, Hokkaido University for their help in both the field and laboratory activities.

\section{REFERENCES}

Chow, V. 1987. Patterns of growth and energy allocation in northern California population of Littorina (Gastropoda: Prosobranchia). Journal of Experimental Marine Biology and Ecology, 110: 69-89.

Crisp, D. J. 1984. Energy flow measurements. In, Methods for the Study of Marine Benthos, Holme, N. A. and A.D., McIntyre (eds.), IBP handbook No. 16, Blackwell, Oxford, pp. 284-372.

Doughty, P. and R. Shine 1998. Reproductive energy allocation and long-term energy stores in a viviparous lizard (Eulamprus tympanum). Ecology, 79: 1073-1083.

Ekaratne, S. U. K. and D. J. Crisp 1984. Seasonal growth studies of intertidal gastropods from shell microgrowth band measurements, including a comparison with alternative methods. Journal of the Marine Biological Association of the United Kingdom, 64: 183-210.

Erlandsson, J. and K. Johannesson 1994. Sexual selection of female size in marine snail, Littorina littorea (L.). Journal of Experimental Marine Biology and Ecology, 181: 145-157.

Etter, R. J. 1994. The effect of wave action, prey type, and foraging time on growth of the predatory snail Nucella lapillus (L.). Journal of Experimental Marine Biology and Ecology, 196: 341-356.

Feare, C. J. 1970a. The reproductive cycle of the dogwhelk (Nucella lapillus). Proceedings of the Malacological Society of London, 39: 125-137.

Feare, C. J. 1970b. Aspect of the ecology of an exposed shore population of the dogwhelks Nucella lapillus (L.). Oecologia, 5: 1-18.

Feare, C. J. 1971. The adaptive significance of aggregation behaviour in the dogwhelk Nucella lapillus (L.). Oecologia, 7: 117-126.

Fujinaga, K. 1985. The reproductive ecology of the neptunea whelk (Neptunea arthritica Bernardi) population, with special reference to the reproductive cycles, depositions of egg masses and hatchings of juveniles. Bulletin of the Faculty of Fisheries, Hokkaido University, 36: 87-98 (in Japanese).

Fujinaga, K. 1987. On the growth pattern of the neptune whelk Neptunea arthritica Bernardi. Bulletin of the Faculty of Fisheries, Hokkaido University, 38: 191-202.

Gardner, J. P. A and M. L. H. Thomas 1987. Growth, mortality and production of organic matter by a rocky intertidal population of Mytilus edulis in the Quoddy region of the Bay of Fundy. Marine Ecology Progress 
Series, 39: 31-36.

Goodwin, B. J. 1978. The growth and breeding cycle of Littorina obtusata (Gastropoda: Prosobranchia) from Cardigan Bay. Journal of Molluscan Studies, 44: 231242.

Goshima, S., K. Nagamoto, K. Kawai and S. Nakao 1991. Reproductive cycle and growth of the northern great tellin, Megangulus venulosus, in Shiriuchi, Hokkaido. Benthos Research, 40: 23-33 (in Japanese).

Gosselin, L. A. and E. Bourget 1989. The performance of an intertidal predator Thais lapillus in relation to structural heterogeneity. Journal of Animal Ecology, 58: 287-303.

Harding, J.P. 1949. The use of probability paper for the graphical analysis of polymodal frequency distributions. Journal of the Marine Biological Association of the United Kingdom, 28: 141-152.

Hughes, R. N. 1986. A functional biology of marine gastropods. Croom Helm, London \& Sydney, 245 pp.

Kawai, K. 1993. Ecological energetics of the dogwhelk Nucella freycineti (Deshayes) population. Ph.D. thesis, Hokkaido University, 150 pp (in Japanese).

Kawai, K. and S. Nakao 1993. Reproductive cycle, copulating activity and dispersal pattern of the dogwhelk Nucella freycineti (Deshayes). Benthos Research, 45: $29-41$.

Kawai, K., S. Goshima and S. Nakao 1993. Reproductive cycle and shell growth of the tellin Nitidotellina nitidula (Dunker) in Hakodate Bay. Bulletin of the Faculty of Fisheries, Hokkaido University, 44: 105-115.

Largen, M. J. 1967. The diet of the dog whelk, Nucella lapillus (Gastropoda, Prosobranchia). Journal of Zoology (London), 151: 123-127.

Moore, J. B. 1938. The biology of Purpura lapillus. III . Life history and relation to environmental factors. Journal of the Marine Biological Association of the United Kingdom, 23: 57-74.

Moreau, J. 1987. Mathematical and biological expression of growth in fish: Recent trends and further developments. In. Age and Growth of Fish, Summerfelt, R. C. and G. E. Hall (eds.), Iowa State Univ. Press, pp. 81113.
Okumura, H. 1986. Introduction to data analysis by computer, Gijyutsu Hyouron Nyuumon, Tokyo, 244 pp (in Japanese).

Palmer, A. R. 1983. Growth rate as a measure of food value in thaidid gastropods: Assumptions and implications for prey morphology and distribution. Journal of Experimental Marine Biology and Ecology, 73: 95-124.

Pearce, J. B. and G. Thorson 1967. The feeding and reproductive biology of the red whelk, Neptunea antiqua (L.) (Gastropoda, Prosobranchia). Ophelia, 4: 277-314.

Roff, D. A. 1992. The evolution of life histories. Chapman and Hall, New York, 535 pp.

Staikou, A., M. Lazaridou-Dimitriadou and E. Pana 1988. The life cycle, population dynamics, growth and secondary production of snail Bradybaena fruticum (Müller, 1774) (Gastropoda Pulmonata) in northern Greece. Journal of Molluscan Studies, 56: 137-146.

Stearns, S. C. 1994. The Evolution of Life History. Oxford University Press, New York, 249 pp.

Stickle, W. B. 1973. The reproductive physiology of the intertidal prosobranch Thais lamellosa (Gmelin) I. Seasonal changes in the rate of oxygen consumption and body component indexes. Biological Bulletin, 144: 511-524.

Tamai, K. 1988. Estimation of productivity of benthos. Kaiyou to Seibutu, 11: 49-53 (in Japanese).

Tsutsumi, A and M. Tanaka 1987. Analysis of population dynamics of polychaete. Benthos Research, 31: 18-28 (in Japanese).

Uno, Y. 1962. Studies on the aquiculture of Turbo cornutus Solander with special reference to the ecology and periodicity of the growth. Journal of the Tokyo University of Fisheries, 6: 1-76 (in Japanese).

Webber, H. H. 1970. Changes in the metabolite composition during the reproductive cycle of the abalone Haliotis cracherodii (Gastropoda: Prosobranchia). Physiological Zoology, 43: 213-231.

Williamson, P. and M. Kendall 1981. Population age structure and growth of the trochid Monodonta lineata determined from shell rings. Journal of the Marine Biological Association of the United Kingdom, 61: 10111026. 